\title{
Beaterio de arrepentidas de Santa María la Blanca, según sus Constituciones (siglos XVI y XVII)
}

\section{Penitent Women in the Beaterio of Santa Maria la Blanca, according to its Constitutions (16 ${ }^{\text {th }}$ and $17^{\text {th }}$ century)}

\author{
$M^{a}$ Elena Aguado SÁnchez \\ elena.aguado@hotmail.com
}

Fecha de recepción: 19-06-2018

Fecha de aceptación: 05-12-2018

\section{RESUMEN}

Las reglas que regían las mancebías en el siglo XVI obligaban a las meretrices a dejar de trabajar en Cuaresma y Semana Santa. Durante este tiempo se recogían en hospitales o en casas honestas y acudían a las iglesias donde por medio de los sermones eran invitadas a dejar su oficio y comenzar un camino de conversión. Ante la demanda de un lugar donde poder recoger definitivamente a estas mujeres, que querían dejar la prostitución, el cardenal Juan Martínez de Silíceo fundó en Toledo una institución benéfica para tal fin. Fue ubicada en la judería, en unas casas junto a la capilla de Santa María la Blanca la antigua sinagoga convertida al culto cristiano que formaba parte de sus instalaciones. Estas mujeres ingresaban de forma voluntaria, se las instruía, y cuidaban de que no volviesen a tener relación con su vida anterior. Esta institución, establecida como colegio de Nuestra Señora de la Piedad, fue conocida popularmente como beaterio de santa María la Blanca o Refugio de la Penitencia. El fin de este trabajo es conocer los inicios de este lugar y la forma de vida de las mujeres que lo habitaron, por medio del estudio de sus constituciones.

Palabras clave: Arrepentidas, beaterio, judería

Topónimos: Toledo

Período: Edad Moderna

\section{ABSTRACT}

The rules that governed brothels in the 16th century forced prostitutes to stop working during Lent and Holy Week. During this period they assembled in hospitals or in honest homes and went to the churches where they were invited to abandon their profession and begin a path of conversion. Given the increasing demand for a home for these women, Cardinal Juan Martínez de Silíceo founded a charitable institution in Toledo. It was located in the Jewish quarter, in some houses next to the chapel of Santa María la Blanca, the former synagogue converted to Christian worship. These women entered voluntarily, were educated, and helped not to relapse into their previous conduct. 
This institution, established as the School of Nuestra Señora de la Piedad, was popularly known as Beaterio de Santa María la Blanca or Refuge of Penitence. The purpose of this work is to discover the origins of this place and the way of life of the women who inhabited it, through a study of its constitutions.

Key words: Penitent, beaterio, Jewish quarter

Place names: Toledo

Period: Modern Age

\section{INTRODUCCIÓN}

Tras la expulsión de los judíos en 1492 los espacios en la judería se transformaron y, por ende, la función de muchos de sus edificios. Los lugares públicos, en manos de la monarquía, fueron vendidos o donados a terceros. Las sinagogas, lugares de oración para los judíos, quedaron arruinadas y en su lugar se levantaron otros edificios ${ }^{1}$. Algunas se conservaron restituidas para el culto cristiano. Fue el caso de la conocida como Santa María la Blanca, aunque sufrió distintas transformaciones tal como rezaba en una leyenda que estuvo situada a los pies de la nave hasta finales del siglo XIX². Reproducida por todos aquellos que han querido relatar su historia, esta inscripción era el compendio de las distintas etapas que fueron determinando la estética de este edificio. Amador de los Ríos señalaba "si se cuidasen de poner en todos los monumentos inscripciones parecidas a esta, mucho tendrían que agradecerlo los viajeros" 3 . Varios autores se apoyaron en esta para aportar alguna noticia histórica sobre la institución que nos ocupa, a pesar de que los puntos relativos a cronología, tipo de establecimiento y advocación eran erróneos.

Si tenemos en cuenta los datos aportados por autores contemporáneos, la fundación se efectuó en 1550 y se trasladó anexa a Santa María la Blanca en 1554. Del mismo modo, como explicare a continuación, otros documentos ratifican que su existencia se prolongó más allá de 1600. Las mismas fuentes se refieren a este lugar como beaterio, casa de recogidas, casa de arrepentidas, e incluso monasterio. Denominaciones que corresponden a diferentes tipologías y que debemos definir para poder centrar el tema. En cuanto a la advocación también es confusa pues se conoce como beaterio de Santa María la Blanca o casa de la Penitencia, aunque el título elegido por su fundador fue el de colegio de Nuestra Señora de la Piedad.

1 R. Izquierdo Benito, "Pervivencia de los lugares de culto en Toledo y su entorno durante la Edad Media", en Sacra loca toletana: Ios espacios sagrados en Toledo, Cuenca, Universidad de Castilla la Mancha, 2008, pp. 153-154.

2 "Este edificio fue sinagoga hasta los años de 1405, en que se consagró en iglesia con título de Sta. María de la Blanca, por la predicación de S. Vicente Ferrer. El cardenal Silíceo fundó en ella un monasterio de religiosas con la advocación de la Penitencia en el de 1500. En el de 1600 se suprimió y se redujo a ermita u oratorio, en cuyo destino permaneció hasta el de 1791, en que se profanó y convirtió en cuartel por falta de casas; y en el de 1798, reconociéndose que amenazaba próxima ruina, dispuso el señor don Vicente Domínguez de Prado, intendente de los reales ejércitos y general de esta provincia, su reparación, con el fin de conservar un monumento tan antiguo y digno de que haga memoria en la posteridad, reduciéndole en almacén de enseres de la real hacienda, para que no tenga en lo sucesivo otra aplicación menos decorosa" en J. López de Ayala y Álvarez de Toledo, Toledo. Guía histórico-práctica por el vizconde de Palazuelos, Toledo, Menor Hermanos, 1890, pp. 595-596.

3 J. Amador de los Ríos y Serrano, Toledo pintoresca o Descripción de sus más célebres monumentos, Ignacio Boix, 1845, p. 235. 
Mi propósito es analizar estos tres puntos puesto que plantean muchas incógnitas. A través de la historiografía y el traslado de las constituciones de esta institución iré argumentando cada una de las hipótesis que se vayan planteando. Para concluir, y apoyándome en las mismas fuentes, trataré de reconstruir la forma de gobierno y vida de las mujeres que habitaron la casa.

\section{HISTORIOGRAFÍA Y FUENTES}

En el momento de compilar las noticias que existen sobre la institución que nos ocupa he constatado que las fuentes son escasas y fundamentalmente generadas por el interés artístico del edificio que formó parte de sus instalaciones como iglesia: la sinagoga de Santa María la Blanca 4 . He aprovechado esta coyuntura para realizar una revisión historiográfica que pueda aportar más información de los tiempos en los que formó parte de la casa de recogidas. Se trata de un trabajo complejo pues, como ya he señalado, son pocas las noticias con las que contamos 5 .

Inciertos son sus orígenes y uno de los principales problemas es la identificación de la sinagoga. León Tello cree que se trata de "la Nueva", construida por Yosef ibn Sosan a finales del siglo XII6. En cambio, Monterreal Gil afirma que es "la Mayor" que cantara Yacob Albeneh en el Elogio de los mártires de Toledo. Teoría asentada por González Simancas, Torres Balbás y Passini. En cuanto a la adscripción artística, decía Pérez Galdós que "el hebreo no tiene arte porque no tiene territorio"8 y vinculaba el edificio al estilo musulmán. Era el sentir general de los intelectuales de finales del XIX que llegaron

4 Para el estudio de la judería toledana y sus sinagogas: J. Passini, La Judería de Toledo, Toledo, Sofer, 2011; J. Passini y R. Izquierdo Benito (coords.), La judería de Toledo, un tiempo y un espacio por rehabilitar. Actas del XXI curso de Cultura Hispanojudía y Sefardí, Ciudad Real, Universidad de Castilla La Mancha, 2014; M. Cortés Arrese, "Sinagogas y juderías de Toledo" en Enciclopedia de Castilla La Mancha, Madrid, Ediciones Corporativas, 1999, vol. 7, p. 56; O. Monterreal Gil, La judería de Toledo en la Edad Media: el arte en su entorno, tesis doctoral dirigida por S. Calvo Capilla y J. C. Ruiz Souza, Universidad Complutense de Madrid, 2015, https://eprints.ucm.es/32928_(Consulta: 30-06-2017); S. Palomero Plaza, Historia de la Sinagoga de Samuel Ha Leví y del Museo Sefardí de Toledo, Madrid, Ministerio de Cultura, 2007; M. González Simancas, Las sinagogas de Toledo y el baño litúrgico judío, Zaragoza, Riopiedras, 2015. De interés para los estudios de arte: B. Caviró, "El arte mudéjar y las sinagogas toledanas" en Luz de sus ciudades: homenaje a Julio Porres Martín-Cleto, Toledo, Diputación, 2008, pp. 331-365; B. Pavón Maldonado, "Las sinagogas de Santa María la Blanca y el Tránsito de Toledo a examen: la arquitectura y la decoración post Almohade en Castilla", en http:// www.basiliopavonmaldonado.es/public/ineprueba.htm (Consulta: 16-02-2018). Para el conocimiento de la vida de los judíos toledanos a través de los textos es interesante el trabajo de P. León Tello, Judíos de Toledo, Madrid, Consejo Superior de Investigaciones Científicas, 1980. En cuanto B. Palomares Sánchez, Antigua sinagoga de santa María la Blanca, Córdoba, Ediciones Almendro, 2009 es fundamental para descubrir las transformaciones sufridas por el edificio.

5 Es difícil encontrar bibliografía que trate el edificio en época del beaterio. Algunas páginas en F. Marías Franco, La arquitectura del renacimiento en Toledo (1541-1631), Toledo, Instituto Provincial de Investigaciones y Estudios Toledanos, 1983, vol. III. Por este motivo justifico la utilización de obras anteriores al siglo XX que me han ayudado a componer la historia de la sinagoga en el tiempo que nos ocupa.

6 P. León Tello, Judíos de Toledo... vol. I, pp. 44 y 176. Se apoya en la inscripción de un epitafio publicado en F. Cantera Burgos y J.M. Millás Vallicrosa, Las inscripciones hebraicas en España, Madrid, Centro Superior de Investigaciones Científicas, 1956, pp. 62 - 64.

7 O. Monterreal Gil, La judería de Toledo..., pp. 319-320.

8 B. Pérez Galdós, Toledo su historia, su leyenda: las generaciones artísticas en la ciudad de Toledo, Toledo, Antonio Pareja editor, 2000, p. 78. 
a catalogarlo como mezquita ${ }^{9}$. Manuel de Assas $^{10}$ situó la construcción en época califal y como muestra de buena convivencia por la ayuda que los judíos proporcionaron a los musulmanes para ocupar la ciudad. Justificaba la decoración, indiscutiblemente posterior, al embellecimiento del edificio en tiempos de Alfonso VI, Alfonso X o incluso de Pedro I. EI vizconde de Palazuelos señalaba que era una edificación del siglo XIII con decoración del XIV y después del incendio sufrido en el año $1390^{11}$. Los más recientes estudios la sitúan en el siglo XIV, en los parámetros del mudéjar. Si bien, el fin de este trabajo no es el de entrar en debate sobre estas cuestiones.

Se tornó en iglesia y el primero que hizo referencia a su consagración fue Pisa. Señalaba como responsable a san Vicente Ferrer y su vehemencia en los sermones, apoyándose en lo escrito por Alcocer y Beuter ${ }^{12}$. La tradición sitúa a este santo predicando en Santiago del Arrabal y guiando a la turba hacia la sinagoga donde expulsaron a los judíos y posteriormente celebraron misa ${ }^{13}$. Señala León Tello que esto no pudo acontecer antes del verano de 1411 y para tal aseveración se apoya en las Crónicas de Juan $/{ }^{14}$. El primer documento que aporta datos sobre el culto cristiano en este lugar es de $1436^{15} \mathrm{y}$ otro, con quejas de los cofrades de santa María la Blanca, sitúa la consagración en torno a $1397^{16}$. Cualesquiera que sean las fechas parecen anteriores al Decreto de Expulsión de los judíos promulgado por los Reyes Católicos en 1492.

En 1523 se encontraba abandonada pues durante el proceso inquisitorial a Blanca Ramírez, por judaizante, se advirtió que era utilizada por algunos conversos como sinagoga clandestina ${ }^{17}$. En tiempos de Blas Ortiz se conocía como capilla con el título de santa María la Blanca, antiguamente sinagoga de judíos ${ }^{18}$. Poco tiempo después, 1554, se incorporó como iglesia a la institución para mujeres arrepentidas creada por el cardenal Silíceo, como veremos en las siguientes líneas. Este realizó algunos cambios, aunque la planta de la iglesia permaneció igual pues al ser basilical se podía aprovechar para el culto cristiano ${ }^{19}$. Conservó la puerta de acceso en el muro sur, aunque decorándola al estilo renacentista. Actualmente tapiada se conserva flanqueada por dos columnas estriadas que sostienen cornisa y friso sobre el que reza la siguiente invocación: Sancta María Succurre Miseris ${ }^{20}$. Se

9 Se realizó una reconstrucción para dotar al edificio de aspecto de mezquita, aunque se conservaron los elementos cristianos para poder devolverlo al culto y evitar abandono. En B. Palomares Sánchez, Antigua sinagoga..., p. 137.

10 M. Assas, Antigua Sinagoga, hoy iglesia de Santa María la Blanca; y Brocal de un aljibe de la Mezquita aljama toledana, Madrid, José Gil Dorregaray (ed.), 1878.

11 J. López de Ayala y Álvarez de Toledo, Toledo. Guía histórico-práctica..., p. 590.

12 P. A. Beuter, Primera parte de la crónica general de toda España y especialmente del reino de Valencia, Joan de Mey (ed.), 1546, vol. I, p.78.

13 J. Amador de los Ríos, Toledo pintoresca..., p. 276.

14 P. León Tello, Judíos de Toledo..., vol. I, p. 193 - 194.

15 Ibídem, vol. II, p. 237.

16 Ibídem, vol. II, p. 517.

17 Ibídem, vol. I, pp. 357 - 359.

18 Biblioteca Nacional de España (en adelante B.N.E), mss. 9168, p. 307, Descripción del sumo y máximo templo de la santa Iglesia de Toledo y todas las demás cosas que en él hay dignas de saberse por el doctor Blas Ortiz, canónigo de la dicha Iglesia. Existe una edición impresa de esta obra en R. Gonzálvez, La catedral de Toledo, 1549. Según el Dr. Blas Ortiz, Descripción graphica y elegantíssima de la santa Iglesia de Toledo, Antonio Pareja editor, Toledo, 1999.

19 B. Palomares Sánchez, Antigua sinagoga..., p. 109.

20 Santa María Socorre a los Miserables...etcétera, Se trata de una oración de san Agustín que se usa para 
accedía al interior del templo bajando seis peldaños que salvaban la pendiente de la calle y conducía a un vestíbulo de tracería gótica que a juicio de Amador de los Ríos correspondía a la época del beaterio ${ }^{21}$. Refutado por Parro que creía que se realizó en los tiempos que fue ermita, durante el siglo $\mathrm{XV}^{22}$. A los pies de la iglesia, frente al altar mayor, se abrió una nueva puerta ${ }^{23}$ y en el testero de las naves se construyeron tres capillas atribuidas a Alonso de Covarrubias ${ }^{24}$. También de esta época es el retablo de la capilla central realizado por Nicolás de Vergara "el viejo" y Juan Bautista Vázquez ${ }^{25}$ que junto a Luis de Velasco trabajaron en distintas empresas para el cardenal Silíceo ${ }^{26}$.

Consta de dos cuerpos superpuestos, que abarcan en los extremos dos grandes columnas sobre que carga el cornisamiento. El zócalo del primer cuerpo ofrece dos buenos relieves que representan a María Magdalena y a una de las Sibilas. Cuatro esbeltas columnas adornadas con caprichosas figuras forman en este primer cuerpo, de igual modo que en el segundo, tres intercolumnios, de cuyos seis, en los dos centrales que afectan la figura de hornacina, no aparece escultura o relieve alguno. Los cuatro restantes presentan otros tantos asuntos de la vida de Jesucristo: la Anunciación, el Nacimiento, la Adoración de los Reyes y la Huida a Egipto: siendo la ejecución en todos ellos muy regular y esmerada. Sirve de remate al retablo un medallón circular en que va figurada la Trinidad, a que rodean ángeles portadores de los instrumentos de la Pasión: coronándolo aún dos niños o angelillos que sostienen un tarjetón cuya leyenda no es fácil distinguir. Finalmente, en los extremos del cornisamiento, otros dos niños se apoyan en el escudo de Silíceo ${ }^{27}$.

Es coronado por unos angelillos que sostienen un tarjetón con la siguiente leyenda: Oh mors, quam amara est memoria tua ${ }^{28}$. El zócalo del primer cuerpo presenta en uno de los relieves a María Magdalena, pecadora arrepentida, en clara alusión a las habitantes de este lugar ${ }^{29}$.

Amador de los Ríos indicó que el beaterio duró un siglo ya que "dejaron de entrar novicias después de intentar relajar la regla sin éxito"30 y Pisa fechó el final de la institución en 1600. Contradice esta afirmación Castejón y Fonseca que en el año 1646 refería lo deteriorada que se encontraba la hacienda siendo el motivo por el que "esta muy piadosa

la religión agustiniana, según su ceremonial, algunos viernes del año, en F. A. de Gante, El monstruo de África indefinible vida de san Agustín, obispo y doctor de la Iglesia, Madrid, Joachin Ibarra, 1767, p. 336.

21 B. Palomares Sánchez, Antigua sinagoga ..., p. 123.

22 S.R. Parro, Toledo en la mano..., p. 298.

23 B. Palomares Sánchez, Antigua sinagoga ..., p. 125.

24 F. Marías Franco, La arquitectura del renacimiento... vol. III, p. 185.

25 Ibídem, p. 185.

26 A. García García, "El retablo mayor de Villar del Pedroso: algunos aspectos históricos e iconográficos", Revista Arte y Patrimonio, 1 (2016), p. 24.

27 J. López de Ayala y Álvarez de Toledo, Toledo: Guía histórico-práctica..., p. 596. Actualmente en el Altar Mayor de la Iglesia del Salvador de Toledo.

28 J. Amador de los Ríos, Toledo pintoresca..., p. 278. Se trata de un versículo de la Biblia: ¡Oh muerte, ¡qué amargo es tu recuerdo para el que vive tranquilo entre sus bienes, para el hombre despreocupado que prospera en todo y todavía es capaz de saborear la comida!, en Eclesiástico $(41,1)$.

29 María Magdalena era una de las mujeres que acompañaron a Cristo como discípula, estuvo al pie de la Cruz junto a María y Juan, y fue la primera en verle tras la Resurrección. Tradicionalmente se ha identificado con la pecadora arrepentida del Evangelio de san Lucas $(7,36-50)$ y por eso muchos de estos lugares se denominaron bajo su advocación. No obstante, tal relación es un error puesto que son dos personas distintas. 30 J. Amador de los Ríos, Toledo pintoresca..., p. 235. 
obra no ha crecido como nos pudiéramos prometer de su Instituto"31 y advirtiendo que aún permanecía el "convento". Bécquer marcó 1791 como año en que se desacralizó la iglesia y que el retablo llegó a la parroquia de Santiago del Arrabal ${ }^{32}$. En 1882 aparecía en la leyenda del plano de Reinoso como "exconvento de arrepentidas de santa María la Blanca"33.

En los últimos años los estudios sobre la mujer están aportando mucha información sobre estos lugares que servían para corregir ${ }^{34}$. La prostitución no era un delito y las mancebías se regulaban por las ordenanzas de la de Sevilla desde $1571^{35}$. No obstante, era pecado y las meretrices comenzaron a ser recluidas por voluntad social para reprimir su comportamiento ${ }^{36}$.

31 D. de Castrejón y Fonseca, La primacía de la Santa Iglesia de Toledo, su origen, sus medras, sus progresos en la continua serie de prelados que la gobernaron, y a la vista de las mayores persecuciones de la católica religión: defendida contra las impugnaciones de Braga, Madrid, D. Diaz de la Carrera, 1646, pp. 1056-1057.

32 G. A. Bécquer, Templos de Toledo: San Juan de los Reyes, Madrid, Nieto y compañía, 1857, pp. 55-57. A finales del siglo XIX volvió establecerse el culto cristiano y llevaron el altar que se encontraba en San Pedro Mártir, el retablo que estaba guardado en San Bartolomé y la escultura de la Virgen Blanca, con sus joyas, custodiada en Santo Tomé en B. Palomares Sánchez, Antigua sinagoga..., pp. 94-95.

33 Archivo Municipal de Toledo (en adelante A. M. T.), cartografía histórica, plano-guía de la ciudad de Toledo por José de Reinoso, 1882.

34 Pioneros en este tipo de estudios A. Domínguez Ortiz, "La galera o cárcel de mujeres de Madrid, a comienzos del siglo XVIII", Anales del Instituto de Estudios Madrileños, 9 (1973), pp. 277-285, que nos descubre los motivos del fracaso de las casas de recogidas y la tipología en la que derivaron a partir del siglo XVIII y J. Muriel de la Torre, Recogimientos de mujeres: Respuesta a una problemática social novohispana, México, Instituto de Investigaciones Históricas, 1974. En el contexto de la prostitución: F. Vázquez García y F. Moreno Mengíbar, Poder y prostitución en Sevilla, Sevilla, Universidad de Sevilla, 1998. Sobre comunidades femeninas: A. Muñoz Fernández, Beatas y santas neocastellanas: ambivalencias de la religión y políticas correctoras del poder (siglos XIV-XVI), Madrid, Comunidad de Madrid, 1994. Es imprescindible hacer referencia a M. D. Pérez, "Orígenes de los recogimientos de mujeres", Cuadernos de Historia Moderna y Contemporánea, 6 (1985), pp. 13-24 y A. Morel D’Arleux, "Recogimientos y cofradías del "pecado mortal" en La prostitution en Espagne de l'époque des rois catholiques á la II repûblique, Annales Littéraires de L'université de Besaçon, Centre de Recherchers Sur L'Espagne Moderne, París, 1994, v. II, pp. 111-135. Abundantes son los trabajos sobre las distintas tipologías en la geografía hispana: J. L, de las Heras, "Casas de recogidas y galeras de mujeres en la Edad Moderna: moralidad, asistencia y represión contra las mujeres de los siglos XVII y XVIII" en Mujeres en riesgo de exclusión social y violencia de género, León, Universidad de León, 2014, pp. 417-426; J. Pérez Morera, "El claustro doméstico: beaterios y emparedamientos", Anuario del Instituto de Estudios Canarios, 40 (1996), pp. 23-28; M. I. Pérez de Colosía Rodríguez, "Constituciones para la casa de recogidas fundada por fray Alonso de santo Tomás", Estudios de Arte, Geografía e Historia, 25 (2003), pp. 575-588; M. Fernández Cucala, "La casa de recogidas de Nuestra Señora de la Caridad del Refugio (1848-1870)", Historia Contemporánea, 21 (2000), pp. 485-521; F. Morand, "El papel de las monjas en la sociedad española del setecientos", Cuadernos de Historia Moderna, 29 (2004), pp. 45-64; J. Seguí Santos, "La casa de Arrepentidas: notas acerca de la acción caritativa y social en la Valencia de mediados del siglo XVI", Saitabi: Revista de la Facultad de Geografía i Història, 64-65 (2014-2015), pp. 127-150; M. J. Lop Otín, "El convento de Recogidas de Zaragoza", Boletín del Museo e Instituto Camón Aznar, 97 (2006), pp. 147-172; M. D. Pérez Baltasar, Mujeres marginadas: las casas de recogidas en Madrid, Madrid, 1984; M. C. Gómez García, Mujer y clausura: conventos cistercienses en la Málaga Moderna, Málaga, Universidad de Málaga, 1997; R. Cuartero Arina, Mujeres transgresoras: el delito sexual en la Zaragoza de los siglos XVI y XVII, tesis doctoral dirigida por E. Solano Camón, Universidad de Zaragoza, 2013, https://zaguan. unizar.es/record/10396/files/TESIS-2013-038.pdf (Consulta: 26-10-2018). Especialmente M. Torremocha Hernández, "Donde se recogen las mujeres herradas yncontinentes. Prostitución: acción y represión social en el Antiguo Régimen" en La respuesta social a la pobreza de la Península Ibérica durante la Edad Moderna, León, Universidad de León, 2014, pp. 299-330 e Ibídem, De la mancebía a la clausura: la casa de recogidas de la Magdalena de san Jerónimo y en el convento de san Felipe de la Penitencia (Valladolid siglos XVI-XIX), Valladolid, Universidad de Valladolid, 2014.

35 M. Torremocha Hernández, De la mancebía..., p. 18.

36 Ibídem, p. 39. 
Las características de cada uno de estos centros, en algunos casos similares, y el uso indistinto al mencionarlos hace que sea difícil la definición. Quizá el criterio de clasificación más claro es aquel que los identifica por sus funciones de corrección, prevención o castigo ${ }^{37}$.

Las casas de recogidas surgieron para reformar la conducta de vagabundas y prostitutas como centros de corrección. Eran encerradas contra su voluntad hasta que se consideraban recuperadas para volver a vivir en sociedad. Ciudades como Barcelona o Valencia contaron desde el siglo XIV con este tipo de instituciones que fueron desapareciendo por falta de recursos o por transformarse en conventos $^{38}$. Esta tipología se restauró durante el siglo XVI por iniciativa de particulares o cofradías de carácter benéfico. Una de las primeras fue la que patrocinó en Madrid el cardenal Cisneros. Era conocida como la cofradía de la Madre de Dios que tenía como fin salir de noche y retirar de las calles a vagabundos y mujeres perdidas $^{39}$. En la ciudad de Toledo la cofradía de la santa Caridad en sus estatutos del año 1530 también regulaba la recogida de estas mujeres ${ }^{40}$. Eran llevadas a hospitales como el de san Ildefonso, en la parroquia de santa Leocadia, donde se apartaban de "aquella vida infame" y muchas fueron convertidas y casadas $^{41}$. En la ciudad de Málaga la casa de recogidas se vinculó desde sus inicios la Tercera Orden del Carmen, y con el tiempo pasó a la Orden del Císter siendo origen del convento de recoletas ${ }^{42}$.

Las casas de arrepentidas, también centros de corrección, se diferenciaban de las anteriores en que la entrada era voluntaria ${ }^{43}$. Generalmente se nombraban bajo la advocación de María Magdalena o de santa María Egipciaca ${ }^{44}$. La casa de les Repenides de Valencia fue una de las primeras en ofrecer la vida religiosa como modo de conversión ${ }^{45}$.

Con el tiempo, se crearon galeras que eran instituciones más restrictivas, enfocadas al castigo de las formas de vida desordenadas. Se atribuye a Magdalena de san Jerónimo el impulso de este tipo de establecimientos por medio de su obra Razón y forma de la galera y casa Real, que el rey Nuestro Señor manda hacer en estos reinos para castigo de mujeres vagueantes, ladronas, alcahuetas, hechiceras y otras semejantes ${ }^{46}$. No eran lugares para la reinserción social sino para cumplir condenas por algún delito tipificado, que en algunos casos era de carácter sexual o estaba relacionado con estas mujeres.

Junto a las anteriores coexistía el colegio ${ }^{47}$, tipología menos conocida, cuya función era la prevención. Era un lugar donde se recogían mujeres pobres, abandonadas sin recursos, abocadas a la delincuencia y la marginación. El colegio de Nuestra Señora del Refugio de Toledo, impulsado en 1591 por el cardenal Quiroga, fue un centro caritativo para mujeres y sus instalaciones estaban anejas al monasterio de mojas agustinas de san Torcuato ${ }^{48}$.

37 R. Cuartero Arina, "Mujeres transgresoras..., p. 559.

38 A. Morel D'Arleux, "Recogimientos..., p. 119.

39 Ibídem, p. 122.

40 Ibídem, p. 123.

41 L. Hurtado de Toledo, Memorial de algunas cosas notables que tiene la Imperial Ciudad de Toledo, 1576, p. 557.

42 M. C. Gómez García, Mujer y clausura..., pp. 54-60.

43 R. Cuartero Arina, Mujeres transgresoras..., p. 560.

44 M. I. Pérez de Colosía Rodríguez, "Constituciones..., p. 579.

45 J. Seguí Santos, "La casa de Arrepentidas...", p. 137.

46 M. Torremocha Hernández, De la mancebía..., p. 35.

47 "Compañía de gente que se ocupa de ejercicios de virtud, y están todos ellos entre sí unidos y ligados [...] tienen cierto género de clausura religiosa" en S. de Covarrubias Orozco, Tesoro de la lengua castellana $o$ española, Madrid, L. Sánchez (impr.), 1609, p. 223.

48 A. Fernández Collado, La Catedral de Toledo en el siglo XVI: vida, arte y personas, Toledo, Diputación Provincial de Toledo, 1999, pp. 251-252. 
En cuanto a la casa junto a santa María la Blanca es también denominada beaterio por lo que es oportuno precisar sus características. Eran fundaciones de "mujeres para mujeres" que se apartaban del mundo para vivir sin la tutela masculina. Generalmente viudas que se embarcaban en esta empresa en solitario o junto a otras de su familia y pertenecían a un nivel social acomodado ${ }^{49}$. Con el tiempo se fueron instalando en los modos de vida regular terciaria que "les aportaba personalidad jurídica, les dotaba de estabilidad y ampliaba, o al menos facilitaba, sus posibilidades de supervivencia"50. La casa de terciarias de san Francisco de Paula en Toledo, beatas mínimas de Jesús María, se elevó a categoría de monasterio ${ }^{51}$ y se les concedió emitir los tres votos en el año $1539^{52}$. O la comunidad de la Orden tercera de san Francisco en Vallecas, que en el año 1535 tomó el hábito de san Bernardo ${ }^{53}$. En el Concilio Provincial de Toledo de 1582, se elaboró una normativa que requería a las beatas, que habían emitido voto solemne, a guardar clausura ${ }^{54}$. Tras el Concilio de Trento los beaterios fueron obligados a adoptar una regla, unos se convirtieron en conventos y otros desaparecieron.

La primera reseña de la casa de Toledo es muy cercana a su fundación. Alcocer daba cuenta de "una congregación de mujeres recogidas que primero fueron erradas" 55 . Algunos años más tarde, Hurtado de Toledo ${ }^{56}$ daba noticia de un lugar en la ciudad que en sus orígenes había sido una de las sinagogas de la judería convertido en refugio de prostitutas arrepentidas. Lo presentaba como uno de los tres beaterios, junto al de santa Ana y al de san Antonio de Padua, situados en la colación de santo Tomé. En él vivían treinta y seis beatas en extrema pobreza y se mantenían de su labor y de la limosna. Además, pedía colaboración a las gentes piadosas para que el hambre no las hiciera volver a su anterior oficio ${ }^{57}$. Pisa destacó esta empresa entre las realizadas por el cardenal Silíceo que "fundó de su propia renta" el colegio conocido como Doncellas "para cien doncellas de limpio linaje" con patronazgo del rey de Castilla y el arzobispo de Toledo; otro para treinta niños que servían de "clerizones" en la Santa Iglesia y ayudó también a la fundación de santa María la Blanca para mujeres recogidas ${ }^{58}$. El vizconde de Palazuelos situó el albergue de la Penitencia en unas casas junto a san Cebrián.

Porres señaló el interés del archivo de Doncellas Nobles ${ }^{59}$ para el conocimiento de este lugar por la dependencia administrativa que la casa de recogidas tenía de esta otra

49 A. Atienza, Tiempos de conventos: una historia social de las fundaciones en la España Moderna, Madrid, Marcial Pons, 2008, p. 327.

50 A. Muñoz Fernández, Beatas..., p. 64.

51 "Este vocablo, junto al de convento, se utiliza en crónicas y documentos para referirse a beaterios que profesan la Orden tercera" en A. Muñoz Fernández, Beatas..., p. 67.

52 Archivo Histórico Nacional (en adelante A. H. N.), Universidades, carp. 7, doc. 4.

53 A. Muñoz Fernández, Beatas..., p. 77.

54 Ibídem, p. 82.

55 P. Alcocer, Historia o descripción..., libro II, cap. 35, ff. 11-12.

56 Era rector de la parroquia de San Pedro Mártir y fue elegido para responder al cuestionario que Felipe II. El informe de Hurtado se conoce, de manera independiente, como Memorial de algunas cosas notables que tiene la Imperial ciudad de Toledo en F. J. Campos y Fernández de Sevilla, "Un paseo por el Toledo del siglo XVI", Toledo, Cofradía Internacional de Investigadores: discurso de apertura del curso 2000/2001, pp. 9-10.

57 L. Hurtado de Toledo, Memorial..., pp. 546-549.

58 F. de Pisa, Descripción de la Imperial ciudad de Toledo, y Historia de sus antigüedades, y grandeza, y cosas memorables que en ella han acontecido, de los Reyes que se han señoreado, y gobernado en sucesión de tiempo, y de los arzobispos de Toledo, principalmente de los más celebrados, 1600, libro V, cap. XXII, p. 261.

59 El archivo del colegio de Nuestra Señora de los Remedios se encuentra en proceso de descripción en las estancias del Archivo General de Palacio en Madrid. 
institución ${ }^{60}$. El estudio más completo sobre este establecimiento es el realizado por Vizuete Mendoza a partir de los documentos que sobre la prostitución se custodian en el Archivo Municipal de Toledo ${ }^{61}$. Aporta novedades sobre los orígenes de esta institución y sitúa su cierre en fechas posteriores a las propuestas por otros autores. Este último trabajo ha sido fuente de inspiración y guía del que presento a continuación.

\section{EL BEATERIO DE SANTA MARÍA LA BLANCA: SUS CONSTITUCIONES}

Decía Alcocer que la primera propuesta para apartar a las prostitutas del pecado fue idea de un noble toledano en 1538 que consiguió que las Justicias regularan el modo de hacerlas oír misa y sermón los viernes de Cuaresma ${ }^{62}$. Muchas de ellas experimentaron la conversión y fueron recogidas en casas de particulares de vida honesta. En el año 1550 don Juan Martínez Silíceo compró unas casas principales cerca de san Cebrián y otras cuatro anexas donde se instalaron y vivieron de la limosna. Al principio fueron treinta mujeres gobernadas por una hermana mayor que permanecían allí hasta que encontraban un marido para casarlas o bien se quedaban para siempre si así lo querían. El cardenal nombró visitador de la casa a Juan Fernández de Balboa que era administrador del Hospital de Santiago en el que se trataban enfermedades de transmisión sexual ${ }^{63}$.

En el año 1554 este establecimiento se trasladó desde estas casas a otras cerca de la capilla de santa María la Blanca ${ }^{64}$ que habían sido preparadas por el cardenal Silíceo para establecer allí el monasterio conocido como de "las vallecas"65 y que definitivamente se instaló en Madrid.

La vida de la comunidad del colegio de la Piedad para mujeres arrepentidas fue regulada por unas constituciones firmadas por el cardenal en 9 de mayo de $1557^{66}$.

El límite de mujeres que podían vivir en la institución era de cincuenta, debían ser gobernadas por una hermana mayor y controladas por una portera, ambas cristianas viejas, que guardaban el Estatuto de limpieza de sangre ${ }^{67}$. No eran admitidas aquellas mujeres que podían tener enfermedades contagiosas o que eran mayores de 45 años. Todas las que ingresaban eran inscritas en un libro ${ }^{68}$ que se guardaba en los archivos de la institución.

60 J. Porres Martín-Cleto, "Nuevos datos sobre santa María la Blanca”, Toletum, 31 (1994), pp. 77-84.

61 J. C. Vizuete Mendoza, "Mancebía y casas de recogidas en el Toledo del siglo de Oro", Ensayos humanísticos: homenaje al profesor Luis Lorente Toledo, Ciudad Real, Universidad de Castilla La Mancha, 1997, pp. 489-504.

62 Anticipándose a la normativa de las mancebías del siglo XVI.

63 P. Alcocer, Historia..., libro II, f. 68.

64 J. López de Ayala y Álvarez de Toledo, Toledo: Guía histórico..., p. 594.

65 P. Alcocer, Historia..., libro II, cap. 39, f. 121.

66 El documento utilizado como base de esta investigación es un manuscrito, en formato libro, con el título de Constituciones de santa María la Blanca. Se estructura en dos partes: la primera un traslado, treinta y seis artículos, ratificado por Diego de Barrasa que consta de siete hojas en pergamino. El resto, en papel, anotaciones de visitas desde entonces hasta los tiempos del cardenal Infante. Custodiado en el fondo antiguo de la Biblioteca de la Universidad de Valladolid (en adelante B. U. V.).

67 Se estableció, en el Cabildo Primado, en el año 1547. Su autor fue Juan Martínez Silíceo, y fue confirmado por Paulo III, mediante bula Decet romanum pontificem de 28 de mayo de 1548. En A. Fernández Collado, Los arzobispos de Toledo en la Edad Moderna y Contemporánea: Episcopologio Toledano, Toledo, Instituto Teológico san Ildefonso, 2017, p. 46.

68 Tenían que anotar el día, mes y año de la entrada, nombre de la recogida, nombres del padre y de la madre y lugar de donde era natural "con fin de conocer quien es cualquiera de las que allí entraren y no haya bandos de linajes y locuras que suele muchas veces embobecer a las mujeres" en B.U.V, Fondo antiguo, U/ bc Ms 389, f. 2. 
Fue voluntad del fundador que profesaran al año de ingresar, aunque algunas debieron optar por el matrimonio y vivir allí hasta conseguir juntar la dote para tal estado. Estaban separadas unas de otras y solo se juntaban para la comida, oración y el sermón ${ }^{69}$. Un fraile de san Agustín, fray Alonso de Herrera, contaba que había convertido a tres mujeres públicas y solicitaba limosna para casarlas y, mientras se encontraban candidatos, la casa de santa María la Blanca era el mejor sitio para custodiarlas ${ }^{70}$. Con el tiempo, este lugar terminó por convertirse en una comunidad religiosa constituida por antiguas meretrices. Recibían la profesión, como en un convento convencional, por el obispo o por el vicario general del arzobispado. Para poder asegurar el conocimiento de las constituciones eran leídas ante la postulante, que juraba guardarlas, antes de la profesión. Cada plaza que quedaba libre, por la muerte de alguna de las recogidas, se tenía que ocupar, inmediatamente, por otra mujer. Estas solo podían ser ocupadas por mujeres de la ciudad de Toledo o del arzobispado. Si alguna de ellas era reincidente en el "pecado de la sensualidad"71, era expulsada sin posibilidad de nueva admisión, aunque hubiera profesado.

En la vida comunitaria una de ellas era la responsable de la cocina y de servir la mesa para comer y cenar. Este oficio tenía una duración de seis semanas y cuando terminaba era ocupado por la siguiente destinada para tal labor. No existía el oficio de lavandera pues cada una se encargaba de lavar y enjabonar su ropa con el fin de no transmitir ninguna enfermedad.

En la vida espiritual contaban con la asistencia de dos capellanes que, además, estaban encargados de las misas diarias en el altar mayor de la iglesia y que también eran los confesores. El Capellán Mayor ostentaba el oficio de mayordomo y tenía su vivienda dentro de la iglesia junto a la Capilla Mayor. También se ocupaba de que todo estuviese preparado para la liturgia. Ambos tenían que ser cristianos viejos y cumplir el Estatuto de limpieza de sangre.

Todos los días, al anochecer, acudían a la iglesia a cantar una salve en romance. Al finalizar, el capellán mayor era el encargado de cerrar y entregar las llaves a la portera a través del torno. De nuevo, a la mañana siguiente debía recoger las llaves para abrir a los fieles. Los sábados, días dedicados a la Virgen María, los domingos, Pascuas y otras fiestas, se cantaba el Oficio Divino. El celebrante daba tono en el Evangelio, oraciones, prefacio y Padre Nuestro y las mujeres contestaban. En estos días siempre había predicación realizada por sacerdotes ajenos a la institución que tenían que ser cristianos viejos y que cobraban dos reales. Todos estos sermones tenían como misión la conversión y los temas eran señalados por el obispo o el vicario general del arzobispado.

Durante la comida y la cena en el refectorio se leía sobre vidas de santos u otros libros de devoción recomendados por el arzobispo. Tras la comida o cena volvían al coro para cantar el siguiente himno: "Por cuanta más razón y obligación nosotras pecadoras lastimadas [...] debiéramos de rodillas caminar hasta llegar a los pies de vos serenísima madre de Dios, pecho por tierra para os suplicar pidáis a vuestro benditisimo $[\ldots]^{72 "}$.

Las visitas en la clausura estaban prohibidas y especialmente para los hombres con la excepción del médico, cirujano o confesor, aunque cuando era estrictamente necesario. Tenían que ir acompañados por la guarda que delante de ellos iba tocando una campanilla y de igual forma la salida. Los que tenían algún negocio con la hermana mayor o alguna

69 P. Alcocer, Historia o descripción..., libr. II, cap. 35, fol. 118.

70 J.C. Vizuete Mendoza, "Mancebía..., p. 499.

71 B.U.V, Fondo antiguo... f. 7.

72 Ibídem., f. 4 bis. 
otra debían hacerlo siempre a través del locutorio o torno. Y para tener acceso debían de pedir licencia a la hermana mayor. Si era concedida, la conversación era vigilada por la escuchadera que registraba solamente se atendieran "cosas cristianas y virtuosas". Permitían visitas a las mujeres horradas para ver las labores en las que se ocupaban, sustento de la comunidad, o para oír la lección. Todos estos mandatos correspondían con los que se exigían a los beaterios y conventos.

Para introducir las provisiones la hermana mayor entregaba al capellán las llaves de las bodegas bajas. Este abría la puerta y vigilaba que todo se introdujese correctamente y a continuación volvía a cerrar y entregaba la llave a la hermana mayor. La carne y el pan tenían otro protocolo y se entregaban a través del torno.

Silíceo dispuso que no se podía enterrar nadie en la Capilla Mayor pues la quería para él. La celebración de la misa, cada día, delante de su busto con un responso por su alma, deudos y las almas del purgatorio ${ }^{73}$. Se podía enterrar a otros señores en el resto de las capillas que además dotarían un juro perpetuo para la fábrica de la iglesia y del colegio. Los ornamentos, cálices, y vinagreras tenían que estar en un armario cerrado con llave en las capillas correspondientes.

Era fundamental que no se olvidasen de los mandatos que había dejado el cardenal y por eso las constituciones tenían que leerse todos los días después del anochecer, una vez cerradas las puertas. Estas normas podían ser ampliadas por el obispo siempre que fuese necesario. "En la forma de constituciones y de admitir religiosas ha habido algunas variaciones, y en un tiempo padecieron algunas inquietudes, que con el buen celo se les movieron"74, así expresaba Castrejón y Fonseca los cambios que se realizaron en años posteriores.

Durante la visita realizada por Delgado y Agüero, de parte de Rojas y Sandoval, el 20 de junio de 1604 se aumentaron y endurecieron las normas. El arzobispo se había hecho cargo de una propuesta de recuperación del colegio de arrepentidas y solicitó ayuda económica a las Justicias para que pudiese continuar abierto ${ }^{75}$. En la normativa puso especial empeño en lo referente al sacramento de la Eucaristía que junto con el de la Penitencia debían frecuentar. Su mayor preocupación estaba en el uso que se daba al comulgatorio, pues parece que servía para recibir personas y confesarse a través de él. Encomendó al mayordomo, en un plazo de quince días, poner una reja que impidiera sacar la cabeza a través de este lugar. Encargó a la priora ocuparse de que todas comulgaran y que utilizasen bien este comulgatorio bajo pena de excomunión. También, era responsabilidad de esta prohibir salir de la reja del coro que estaba situada frente al Santísimo. En el caso de dar licencia para transgredir esta norma era castigada con todo rigor en la siguiente visita, además de pasar un día en la cárcel. Como responsable de guardar la clausura, cada noche tenía que recoger las llaves del convento, iglesia, huerto, terrado, torre y las de "las puertas del medio" y mantenerlas en su poder sin fiarlas a nadie ${ }^{76}$.

Reguló el modo de vestir: los tocados tenían que ser blancos y los vestidos honestos y sencillos, los chapines no podían ser más altos de cinco corchos y no estaba permitido lucir anillos, pendientes u otras joyas que se aplicarían para los gastos del convento. En caso de

73 El testamento de Silíceo, fechado en 8 marzo de 1557, expresaba la voluntad de ser enterrado en la Capilla Mayor del colegio de Nuestra Señora de los Remedios. No obstante, su cadáver debía ser depositado en santa María la Blanca hasta que se finalizasen las obras de dicha capilla en A. Fernández Collado, Los arzobispos..., p. 47.

74 D. de Castrejón y Fonseca, La primacía..., pp. 1056- 1057.

75 J. C. Vizuete Mendoza, "Mancebía...”, p. 500.

76 B. U. V, Fondo Antiguo..., f. 9. 
utilizarlos eran castigadas con la prisión o la penitencia que impusiera la priora, y también en la visita. Era motivo de excomunión hacerse las cejas o perfumarse ${ }^{77}$.

Prohibió la entrada en clausura de niños de más de seis años bajo condena de excomunión. La priora seguía siendo la responsable de guardar esta clausura y solo dar licencia, para entrar, a seglares de "vida honesta, buena fama y opinión"78. La visita tenía que ser un lugar, ex profeso, llamado "recibimiento"79. El mayordomo, o los confesores tampoco podían entrar sin licencia del arzobispo, del Consejo o del administrador bajo pena de excomunión. Tanto en la clausura como en la iglesia estaba prohibido tener guitarras, panderetas o cualquier instrumento musical y también bailar. Años atrás se habían instalado en este lugar las religiosas del beaterio de Jesús María ${ }^{80}$.

Insistían en que todas las mujeres tenían que leer, cumplir y guardar las constituciones redactadas por Silíceo. Años más tarde, don Andrés Fernández de Hipessa, inquisidor y vicario general del cardenal Infante, durante la visita realizada el 22 de mayo de 1641, ordenó que para no alegar ignorancia debían leerse tres veces al año y, bajo pena de excomunión mayor lata gententia ipsofacto in currenda ${ }^{81}$, no se podía borrar o tildar el papel donde se encontraban escritas. Subrayaba la importancia del libro de registro de las religiosas al que debían incorporar la fecha de la profesión. Además, tenían que llevar otro libro para asentar los gastos, independiente del que llevaba el mayordomo. Serviría para controlar las entradas de este último ya que solamente eran válidas las partidas escritas de mano de la priora.

Las normas en cuanto a la clausura eran cada vez más restrictivas. No se permitía la entrada de ningún eclesiástico, secular o regular a no ser hermano o tío muy cercano. La priora siempre debía enviar a la escucha y de no ser así era castigada con la excomunión mayor. Tampoco tenía permitida la entrada el mayordomo que si necesitaba sacar una escritura del archivo debía pedir permiso al vicario general e ir acompañado por un sacerdote señalado por este. La entrada de médico, cirujano y confesor sería por necesidad tal como ordenaban las constituciones. En cuanto a la visita de mujeres, hermanas, madres o benefactoras tenían que hacerlo en una sala habilitada para esto y no se les podía permitir circular por el resto de la casa.

En el libro custodiado en Valladolid, fuente de esta investigación, consta como última visita la realizada entre el 15 y 18 de septiembre de 1647 por don Pedro González de las Cuentas ${ }^{82}$. El visitador comprobó si había en los cuartos ventanas por las que se

77 Ibídem, f. 9.

78 B.U.V, Fondo Antiguo..., f. 10.

79 Ibídem, fol. 10.

80 Beatas de la Orden Mínima de san Francisco de Paula que estaban ubicadas en la colación de san Isidro del Arrabal de Toledo. En el año 1534, mediante bula, se les permitió erigir convento y que pudiesen emitir los tres votos de manos de los superiores, recibir hábito y, al año de noviciado, también la profesión. Aunque los mínimos no las querían admitir en el capítulo, por intercesión de la reina Isabel de Valois fueron recibidas en el capítulo de Valencia de 1562. Empobrecidas y sin auxilio de los monjes, el cardenal Gaspar de Quiroga ordenó su traslado al "monasterio de santa María la Blanca". Eran cuatro o seis beatas que vivieron durante algunos años con el hábito de la orden que habían profesado, y algunas de ellas "fueron preladas de aquel santo monasterio, particularmente lo fue algunas veces, la madre María de la Trinidad, persona de mucha virtud y valor" en L. de Montoya, Coronica general de la Orden de los mínimos de S. Francisco de Paula su fundador: Donde se trata de su vida y milagros, origen de la religion, erection de prouincias y varones insignes della, Madrid, 1619, libro I, pp. 380- 381.

81 B.U.V, Fondo Antiguo..., f. 12.

82 Fue nombrado por Pedro Zamora Hurtado que reconoció llevar seis años sin visitar el lugar en Ibídem., fol. 16. 
podían asomar o hablar con gentes. En cuanto a la priora se quejó de la ruina en la que se encontraban algunas casas vecinas y ordenaron se buscaran los propietarios y se les instara a arreglarlas. Esta es la última fecha en que podemos corroborar la permanencia de una comunidad de mujeres heredera de la instituida por el cardenal Silíceo en este lugar.

En el año 1690 las instalaciones amenazaban ruina y se propusieron de nuevo para recoger a mujeres perdidas y vagabundas. Establecimiento que ya no tendría como finalidad la conversión sino revitalizar la industria textil ${ }^{83}$. Esta modalidad había sido propuesta en 1598 por Cristóbal Pérez de Herrera con la denominación de "casas de labor", lugares en que las prostitutas podrían pagar su alojamiento y manutención con trabajos "propios de las mujeres"84.

\section{CONCLUSIÓN}

Este tipo de instituciones fue fruto de una sociedad que pensaba que "los hombres eran responsables directos de sus actos" pero "las mujeres, además, eran responsables de la influencia del comportamiento sobre la moral pública"85. Aquellas que transgredían las normas sociales eran dirigidas a lugares en que se les educaba para poder volver a formar parte de la sociedad, bien como mujeres casadas o como monjas, pues no había otra opción. La casa de arrepentidas fundada por el cardenal Silíceo facilitaba la inclusión social de las prostitutas y fue heredera de las obras sociales que venían realizándose por cofradías y particulares en la ciudad.

En un principio las mujeres entraban de forma voluntaria y arrepentidas de sus actos debían cumplir penitencia, de ahí el apelativo casa de la Penitencia que era como era conocida en sus comienzos junto a la parroquia de san Cebrián.

El Concilio de Trento prohibía la profesión contra la voluntad de las mujeres "exceptuándose, no obstante, las mujeres llamadas penitentes o arrepentidas en cuyas casas se han de observar sus constituciones"86. Y así fue cómo con la consolidación de la fundación junto a santa María la Blanca y con la redacción de las constituciones se les obligó a profesar. Fue instituido como colegio de Nuestra Señora de la Piedad igual que las otras fundaciones benéficas que patrocinó el cardenal en la ciudad de Toledo y entre los propósitos de este lugar estaba el de educar para ser mujeres decentes y virtuosas, con la peculiaridad de que las colegialas eran antiguas meretrices.

Tras la muerte del cardenal y con pocos recursos económicos debió iniciarse un proceso de abandono. Avisado de esta situación el arzobispo Sandoval y Rojas fue impulsor de una nueva etapa en que, a mi juicio, permitió se consolidara como beaterio y se ampliaran las constituciones proporcionando mucha importancia a la clausura. Muy influenciado por el tridentino, instaba a estas mujeres al recato en los vestidos y la frecuencia de los sacramentos, fundamentalmente Penitencia y Eucaristía. La incorporación del beaterio de Jesús María me induce a pensar que esta institución debía tener las mismas características. Suponía un cambio radical al "vivir en extrema clausura y vestidas con hábito"87 y es posible que muchas no resistieran. En posteriores visitas se refieren a ellas como las religiosas y

83 J. C. Vizuete Mendoza, "Mancebía...", pp. 502-504.

84 C. Pérez de Herrera, Discursos del amparo de los legítimos pobres, y reducción de los fingidos; y de la fundación y principio de los albergues de estos reinos y amparo de la milicia de ellos, L. Sánchez, 1598, pp. 63-73.

85 J. L., de las Heras, "Casas de recogidas...", p. 417.

86 El Sacrosanto y Ecuménico Concilio de Trento, I. López de Ayala (trad.), Imprenta Real, 1785, p. 481.

87 E. Rodríguez-Solís, Historia de la prostitución en España y América, Madrid, F. Cao y D. del Val (eds.), 1890-1900, vol. I, p. 74. 
con el paso de los años se denominó convento ${ }^{88}$. No me consta que estuvieran adscritas a ninguna orden, pero la inscripción de la portada y la cercanía al convento de san Agustín me induce pensar en una posible vinculación. Puedo confirmar la existencia de la comunidad, en este lugar, hasta 1647 que es la última fecha apuntada en el libro de las constituciones.

Destaco el interés de esta institución para el conocimiento de los centros de reclusión femenina en la Edad Moderna. La singularidad del edificio que sirvió como iglesia, la desaparición de las estancias conventuales, la dependencia administrativa del colegio de Nuestra Señora de los Remedios y sobre todo el origen de sus moradoras contribuyeron a silenciar la historia de este lugar.

\section{FUENTES}

A.H.N., Rescripto de Pablo III elevando la casa de terciarias de san Francisco de Paula de Toledo, vulgo beatas a la categoría de monasterio y autorizando a emitir los tres votos, Univ., carp. 7, doc. 4.

A.M.T., Cartografía Histórica, Plano-Guía de la ciudad de Toledo por José de Reinoso, 1882. B.N.E., mss. 9168, Descripción del sumo y máximo templo de la Santa Iglesia de Toledo y todas las demás cosas que en él hay dignas de saberse por el doctor Blas Ortiz, canónigo de la dicha Iglesia.

B.U.V., Fondo antiguo, U/bc Ms. 389.

\section{BIBLIOGRAFÍA}

Amador de los Ríos y Serrano, J., Toledo pintoresca o Descripción de sus más célebres monumentos, Ignacio Boix, 1845.

Assas y Ereño, M., Antigua Sinagoga, hoy iglesia de santa María la Blanca; y Brocal de un aljibe de la Mezquita aljama toledana, Madrid, José Gil Dorregaray, 1878.

Atienza López, A., Tiempos de conventos: una historia social de las fundaciones en la España moderna, Madrid, Marcial Pons, 2008.

Bécquer, G. A., Templos de Toledo: san Juan de los Reyes, Madrid, Nieto y compañía, 1857. Beuter, P. A., Primera parte de la crónica general de toda España y especialmente del reino de Valencia, Joan de Mey, 1546, vol. I.

Campos y Fernández de Sevilla, F. J., "Un paseo por el Toledo del siglo XVI", Toledo, Cofradía Internacional de Investigadores: discurso apertura del curso 2000/2001.

Castrejón y Fonseca, D., La primacía de la Santa Iglesia de Toledo, su origen, sus medras, sus progresos en la continua serie de prelados que la gobernaron, y a la vista de las mayores persecuciones de la católica religión: defendida contra las impugnaciones de Braga, Madrid, D. Diaz de la Carrera, 1646.

Covarrubias Orozco, S. de, Tesoro de la lengua castellana o española, Madrid, L. Sánchez, 1609.

Cuartero Arina, R., Mujeres transgresoras: el delito sexual en la Zaragoza de los siglos XVI y XVII; Tesis doctoral dirigida por E. Solano Camán, Universidad de Zaragoza, 2013. https://zaguan.unizar.es/record/10396/files/TESIS-2013-038.pdf (consulta: 2610-2018).

Fernández Collado, Á., Los arzobispos de Toledo en la Edad Moderna y Contemporánea: Episcopologio Toledano, Toledo, Instituto Teológico san Ildefonso, 2017.

- La Catedral de Toledo en el siglo XVI: vida, arte y personas, Toledo, Diputación Provincial de Toledo, 1999.

Fernández Cucala, M., "La casa de recogidas de Nuestra Señora de la Caridad del Refugio (1848-1870)", Historia Contemporánea, 21 (2000), pp. 485-521.

88 B.U.V., Fondo antiguo..., fols. 7-11. 
Gante, F. A. de, El monstruo de África indefinible vida de san Agustín, obispo y doctor de la Iglesia, Madrid, Joachin Ibarra, 1767.

García García, A., "El retablo mayor de Villar del Pedroso: algunos aspectos históricos e iconográficos", Revista Arte y Patrimonio, 1 (2016).

Gómez García, M. C., Mujer y clausura: conventos cistercienses en la Málaga Moderna, Málaga, Universidad de Málaga, 1997.

Heras, J. L. de las, "Casas de recogidas y galeras de mujeres en la Edad Moderna: moralidad, asistencia y represión contra las mujeres de los siglos XVII y XVIII", en Mujeres en riesgo de exclusión social y violencia de género, León, Universidad de León, 2014, pp. 417-426.

Hurtado de Toledo, L. Memorial de algunas cosas notables que tiene la Imperial Ciudad de Toledo,1576.

Izquierdo Benito, R., "Pervivencia de los lugares de culto en Toledo y su entorno durante la Edad Media", en Sacra loca toletana: Ios espacios sagrados en Toledo, Cuenca, Ediciones de la Universidad de Castilla la Mancha, 2008.

León Tello, P., Judíos de Toledo, Madrid, Consejo Superior de Investigaciones Científicas, 1980, vol. I.

Lop Otín, P., "El convento de Recogidas de Zaragoza", Boletín del Museo e Instituto Camón Aznar, 97 (2006), pp. 147-172.

López de Ayala, I. (trad.), El Sacrosanto y Ecuménico Concilio de Trento, Madrid, Imprenta Real, 1785.

López de Ayala y Álvarez de Toledo, J. L., Toledo: Guía histórico-práctica por el vizconde de Palazuelos, Toledo, Hermanos Menor (eds.), 1890.

Marías Franco, F., La arquitectura del renacimiento en Toledo (1541-1631), Toledo, Instituto Provincial de Investigaciones y Estudios Toledanos, 1983, vols. II y III.

Monterreal Gil, O., La judería de Toledo en la Edad Media: el arte en su entorno, Tesis doctoral dirigida por S. Calvo Capilla y J. C. Ruíz Souza, Universidad Complutense de Madrid, 2015, https://eprints.ucm.es/32928/ (consulta: 30-06-2017).

Montoya, L. de, Coronica general de la Orden de los mínimos de S. Francisco de Paula su fundador: Donde se trata de su vida y milagros, origen de la religión, erección de provincias y varones insignes della, Madrid, 1619, libro I.

Morand, F., "El papel de las monjas en la sociedad española del setecientos", Cuadernos de Historia Moderna, 29 (2004), pp. 45-64.

Morel D'Arleux, A., "Recogimientos y cofradías del 'pecado mortal", en Carrasco, R., La prostitution en Espagne de l'époque des rois catholiques á la lla repûblique, París, Annales Littéraires de L'université de Besaçon, Centre de Recherchers Sur L'Espagne Moderne, 1994, v. III.

Muñoz Fernández, A., Beatas y santas neocastellanas: ambivalencias de la religión y políticas correctoras del poder (siglos XIV - XVI), Madrid, Comunidad de Madrid, 1994.

Muriel de la Torre, J., Recogimientos de mujeres: Respuesta a una problemática social novohispana, México, Instituto de Investigaciones Históricas, 1974.

Palomares Sánchez, B., Antigua sinagoga de santa María la Blanca, Córdoba, Ediciones Almendro, 2009.

Palomero Plaza, S., Historia de la Sinagoga de Samuel Ha Leví y del Museo Sefardí de Toledo, Madrid, Ministerio de Cultura, 2007.

Passini, J., La Judería de Toledo, Toledo, Sofer, 2011.

Pérez Baltasar, M. D., "Orígenes de los recogimientos de mujeres", Cuadernos de Historia Moderna y Contemporánea, 6 (1985), pp. 13-23.

- Mujeres marginadas: las casas de recogidas en Madrid, Madrid, 1984. 
Pérez de Colosía Rodríguez, M. I., "Constituciones para la casa de recogidas fundada por fray Alonso de santo Tomás", Estudios de Arte, Geografía e Historia, 25 (2003), pp. 575-588.

Pérez de Herrera, C., Discursos del amparo de los legítimos pobres, y reducción de los fingidos; $y$ de la fundación y principio de los albergues de estos reinos y amparo de la milicia de ellos, 1598.

Pérez Galdós, B., Toledo su historia, su leyenda: las generaciones artísticas en la ciudad de Toledo, Toledo, Antonio Pareja editor, 2000.

Pérez Morera, J., "El claustro doméstico: beaterios y emparedamientos", Anuario del Instituto de Estudios Canarios, 40 (1996), pp. 23-28.

Pisa, F. de, Descripción de la Imperial ciudad de Toledo, y Historia de sus antigüedades, y grandeza, y cosas memorables que en ella han acontecido, de los Reyes que se han señoreado, y gobernado en sucesión de tiempo, y de los arzobispos de Toledo, principalmente de los más celebrados, 1600, libro V.

Porres Martín-Cleto, J., "Nuevos datos sobre santa María la Blanca", Toletum, 31 (1994).

Rodríguez-Solís, E., Historia de la prostitución en España y América, Madrid, F. Cao y D. del Val, 1890-1900, vol. I.

Seguí Santos, J., "La casa de Arrepentidas: notas acerca de la acción caritativa y social en la Valencia de mediados del siglo XVI", Saitabi: Revista de la Facultad de Geografía i Història, 64-65 (2014-2015), pp. 127-150.

Torremocha Hernández, M., "Donde se recogen las mujeres herradas yncontinentes, prostitución: acción y represión social en el Antiguo Régimen" en La respuesta social a la pobreza de la Península Ibérica durante la Edad Moderna, León, Universidad de León, 2014, pp. 299-330.

- De la mancebía a la clausura: la casa de recogidas de la Magdalena de san Jerónimo y en el convento de san Felipe de la Penitencia (Valladolid siglos XVI-XIX), Valladolid, Universidad de Valladolid, 2014.

Vizuete Mendoza, J. C., "Mancebía y casas de recogidas en el Toledo del siglo de Oro", Ensayos humanísticos: homenaje al profesor Luis Lorente Toledo, Ciudad Real, Universidad de Castilla-La Mancha, 1997, pp. 489-504. 